\title{
Phenotypic diversity of patient-derived melanoma populations in stem cell medium
}

\author{
Malgorzata Sztiller-Sikorska', Mariusz L Hartman, Beata Talar ${ }^{1}$, Justyna Jakubowska, Izabela Zalesna and \\ Malgorzata Czyz
}

\begin{abstract}
Melanomas are highly heterogeneous tumors and there is no treatment effective at achieving long-term remission for metastatic melanoma patients. Thus, an appropriate model system for studying melanoma biology and response to drugs is necessary. It has been shown that composition of the medium is a critical factor in preserving the complexity of the tumor in in vitro settings, and melanospheres maintained in stem cell medium are a good model in this respect. In the present study, we observed that not all nodular melanoma patient-derived cell populations grown in stem cell medium were capable of forming melanospheres, and cell aggregates and anchorage-independent single-cell cultures emerged instead. Self-renewing capacity and unlimited growth potential indicated the presence of cells with stem-like properties in all patient-derived populations but immunophenotype and MITF expression exhibited variability. Enhanced MITF expression and activity was observed in melanospheres in comparison with cell aggregates and single-cell culture, and hypoxic-like conditions that increased the ability of single-cell population to form melanospheres enhanced MITF expression and cell pigmentation as well. Thus, MITF seems to be a critical transcription factor for formation of both patient-derived and hypoxia-induced melanospheres. After 2 years of continuous culturing, melanospheres progressively underwent transition into cell aggregates that was accompanied by changes in expression of several MITF-dependent genes associated with melanogenesis and survival and alterations in the composition of subpopulations but not in the frequency of $A B C B 5$-positive cells. Several biological properties of parent tumor are well preserved in patient-derived melanospheres, but during prolonged culturing the heterogeneity is substantially lost when the melanospheres are substituted by cell aggregates. This should be considered when cell aggregates instead of melanospheres are used in the study of melanoma biology and cell response to drugs.

Laboratory Investigation (2015) 95, 672-683; doi:10.1038/labinvest.2015.48; published online 13 April 2015
\end{abstract}

Many cancers, including melanoma, remain incurable. Accumulating evidence suggests that intratumoral heterogeneity and a subpopulation of cancer stem cells (CSCs) play important roles in metastasis formation, multidrug resistance, relapse, and immune evasion. ${ }^{1-7}$ CSCs are subjects of intense study, and several markers, including CD133 (Prominin-1), ATP-binding cassette B5 (ABCB5), the neural crest stem cell marker CD271 (NGFR; p75), and ALDHA1, were considered as useful for isolating melanoma stem-like cells. ${ }^{8-13}$ However, other results argued against a correlation between a specific immunophenotype and stem cell properties. ${ }^{14,15}$ There is no approach that could explicitly reconstitute tumor ex vivo. Therefore, it is still critical to develop a preclinical model that more accurately resembles the complexity of the parent tumor. Xenotransplantation into mice is commonly used to assess tumorigenicity, although it suffers from many inherent limitations. ${ }^{4-6}$ Patient-derived tumor xenografts formed by the transplantation of the tumor fragments into mice harboring a human immune system, and murine and patient trials conducted concurrently, may represent approaches better maintaining intratumor heterogeneity and being more suitable for development of novel therapeutics. ${ }^{16-18}$ In addition to constant progress in in vivo models, in vitro xeno-free strategies aiming to preserve tumor complexity are being developed. ${ }^{19}$ Cancer cell lines, many dating back decades and propagated in vitro as monolayers, are criticized mainly for their lack of heterogeneity and an appropriate tissue structure. We and others have shown that threedimensional spheres maintained in vitro in a serum-free, growth factor-containing stem cell medium (SCM) better recapitulate the parent tumor than monolayers cultured in the presence of serum. ${ }^{20-24}$ 
We have shown that the frequencies of melanoma cells with self-renewing capacity and CD49f-, CD90-, CD133-, and to less extent ABCB5-positive cells vary between patientderived populations. ${ }^{23,25}$ Using transcriptome analyses we have identified MITF and DKK1 as key regulators of microenvironment-dependent phenotypic heterogeneity in vitro. ${ }^{24}$ We observed that the ability to form melanospheres in SCM depends on the sample, and cell aggregates and single-cell culture can arise instead of melanospheres. Therefore, in the present study the properties of patient-derived melanoma cultures capable of forming either melanospheres, cell aggregates, or single-cell populations were compared. Their immunophenotypes and expression and activity of MITF were investigated. Moreover, changes in immunophenotype and gene expression profile were assessed during transition from melanosphere to cell aggregates observed after prolonged culturing. In some experiments, the established cell lines A375, WM793B, and 1205Lu were cultured under conditions suitable for anchorage-independent growth and expression and activity of MITF were investigated.

\section{MATERIALS AND METHODS}

\section{Tumor Tissues and Cell Lines}

Melanoma specimens classified histopathologically as clinical stages III and IV and various TNM staging ${ }^{23,25}$ were obtained during surgical procedures. The study was approved by Ethical Commission of Medical University of Lodz. Informed consent was obtained from the patients. The melanoma specimens were named DMBC2, DMBC8, DMBC9, DMBC10, and DMBC12 (Department of Molecular Biology of Cancer $(\mathrm{DMBC}))$. Immunohistochemical staining with Melan-A (DAKO, Denmark) was performed using sections of formalin-fixed, paraffin-embedded melanoma specimens (FFPE) according to a standard procedure. Sections of DMBC8 were not available. Cell line WM793B was obtained from ATCC (American Type Culture Collection, Manassas, VA, USA), and cell lines A375 and 1205Lu were a gift from Professor Piotr Laidler (Jagiellonian University, Poland).

\section{Cell Culture}

Melanoma cells were isolated from surgical specimens and maintained in SCM in an anchorage-independent manner as described previously. ${ }^{23}$ After several washes, tumor fragments were minced with scissors and incubated in HBSS (SigmaAldrich, St Louis, MO, USA) supplemented with $3 \mathrm{~mm}$ calcium chloride and $1 \mathrm{mg} / \mathrm{ml}$ collagenase IV for $2-3 \mathrm{~h}$ at $37^{\circ} \mathrm{C}$. DNase I $(10 \mu \mathrm{g} / \mathrm{ml})$ was added and cells were filtered through a $70 \mu \mathrm{m}$ pore size filter. Cells were cultured in complete medium (RPMI-1640 with 10\% FBS) for 1 day to remove dead and nonadherent cells. They were transferred to serum-free SCM, consisting of DMEM/F12 low osmolality medium (Lonza, Basel, Switzerland) in the presence of B-27 supplement (Gibco, Paisley, UK), growth factors $(10 \mathrm{ng} / \mathrm{ml}$ bFGF and $20 \mathrm{ng} / \mathrm{ml} \mathrm{EGF;} \mathrm{BD} \mathrm{Biosciences,} \mathrm{San} \mathrm{Jose,} \mathrm{CA,} \mathrm{USA),}$ insulin $(10 \mu \mathrm{g} / \mathrm{ml})$, heparin $(1 \mathrm{ng} / \mathrm{ml})$, and antibiotics
(100 IU/ml penicillin, $100 \mu \mathrm{g} / \mathrm{ml}$ streptomycin, and $2 \mu \mathrm{g} / \mathrm{ml}$ fungizone). Cell cultures were maintained in low-adherent flasks (NUNC) at $37^{\circ} \mathrm{C}$ in a humidified atmosphere containing $5 \% \mathrm{CO}_{2}$. Twice a week medium was exchanged. Every few weeks, single-cell suspensions were generated by enzymatic digestion of melanospheres with $1 \mathrm{mg} / \mathrm{ml}$ collagenase IV. Cell lines A375, WM793B, and 1205Lu were maintained under the same conditions.

\section{Optimizing Conditions for Hypoxia}

First, different concentrations of deferoxamine mesylate (DFO) (Sigma-Aldrich) and exposure time were tested. Then, DFO at $100 \mu \mathrm{M}$ given for 1 day was chosen for further experiments. Microphotographs of cells were taken to visualize the formation of spheres.

\section{Microscopy}

Changes in cell morphology were registered with a digital Olympus camera (C-5050) attached to Olympus microscope (CKX41). Adipocytes were detected with Oil Red O staining. Briefly, adherent cells were rinsed with PBS, fixed with $10 \%$ formalin, stained with $0.3 \%$ Oil Red O in $60 \%$ isopropanol, then counterstained with hematoxylin, and subjected to microscopic analysis.

\section{Flow Cytometry}

Primary antibodies against GD2 (unconjugated), CD20, CD34, and CD166 (PE-conjugated), and CD90 and Tra-181 (FITC-conjugated) were from BD Pharmingen (San Jose, CA, USA), CD133 (PE-conjugated) was from Miltenyi Biotec (Bergisch Gladbach, Germany), nestin and Oct-3/4 (PEconjugated) and CD49f (FITC-conjugated) were from R\&D Systems (Minneapolis, MN, USA), CD31 (FITC-conjugated) was from eBioscience (San Diego, CA, USA), Melan-A and gp100 (clone HMB45) (unconjugated) were from DAKO (Glostrup, Denmark), ABCB5 (unconjugated) was from Sigma-Aldrich, and vWF (unconjugated) from Millipore (Bedford, MA, USA). Anti-GD2, gp100, and Melan-A were detected with FITC-conjugated goat anti-mouse secondary antibody, and anti-ABCB5 and vWF with FITC-conjugated goat anti-rabbit secondary antibody (both from BD Pharmingen). Dead cells were excluded from the analysis by 7-aminoactinomycin D (7-AAD) staining (eBiosciences). Isotype controls were included in each experiment. For intracellular staining, cells were fixed with $4 \%$ paraformaldehyde and permeabilized with $0.1 \%$ Triton X-100 in PBS for $20 \mathrm{~min}$. Typically, 30000 cells were analyzed. Flow cytometric data were acquired with FACSCalibur and FACSVersa (BD Biosciences), and analyzed using BD FACSuite software.

\section{RNA Isolation, CDNA Synthesis, and Real-Time PCR}

RNA isolation, cDNA synthesis, and real-time PCR (qRTPCR) experiments were performed as described previously. ${ }^{26}$ The primers used for qRT-PCR were provided elsewhere. ${ }^{24}$ The annealing temperature was $56^{\circ} \mathrm{C}$. To calculate the 
relative expression of target genes versus a reference gene RPS17, a mathematical model including an efficiency correction for real-time PCR was used.

\section{RESULTS}

\section{Cells from Surgical Melanoma Specimens Have Different Capacity to Form Melanospheres}

We focused our study on nodular melanoma (NM), the most aggressive form of this cancer, accounting for $15 \%$ of all diagnosed melanomas. All samples were Melan-A positive (Figure 1), although the IHC staining of the DMBC12 section was more focal and less intense than that of other melanoma samples. Patient-derived melanoma cells were grown in SCM as anchorage-independent populations continuously, without freezing, for $>2$ years. This indicates that these melanoma populations contained stem-like cells with unlimited proliferative potential, necessary for long-term growth. Melanoma cultures showed diverse morphologies. DMBC8 and DMBC10 cells formed very dense melanospheres that could be dissociated only when prolonged enzymatic digestion was applied. Melanospheres formed by DMBC2 cells were less regular and easier to dissociate, and those formed by DMBC12 should be rather considered as multicellular aggregates as they could be easily dissociated, partially by pipetting. DMBC9 cells grew in an anchorage-independent manner but did not form melanospheres or aggregates (Figure 2). Searching for the marker(s) that could distinguish between cells preferentially forming melanospheres, cell aggregates, and single-cell cultures, their immunophenotypes were investigated. Results of this analysis are shown in Table 1 and in our previous reports. ${ }^{23,25}$ From markers considered previously as cancer stem cell markers, only CD133 seemed to correlate well with the ability to form melanospheres. The populations containing CD133-positive cells exerted a high melanosphere-forming capacity, whereas those lacking CD133-positive cells formed either aggregates (DMBC12) or single-cell culture (DMBC9) (Figure 2).

\section{Hypoxia Mimetic Generates Melanospheres but Does Not Induce Expression of CD133}

DMBC9 cells have been growing continuously as a single-cell population. These cells were transiently exposed to a hypoxia mimetic deferoxamine mesylate (DFO). Not many cells survived that treatment (Figure 3a). A few days after DFO removal, small asymmetric melanospheres were generated (Figure 3b). By day 24, several large spheres of $>100 \mu \mathrm{m}$ in diameter were present in the culture. The enhanced ability of DMBC9 cells to grow as melanospheres was accompanied by a reduction of proliferation rate by a $1.3 \pm 0.1$-fold $(P<0.05)$. No CD133-positive cells, however, appeared in hypoxiainduced melanospheres (not shown), indicating that presence of cells expressing this marker was not absolutely required for melanosphere formation.

\section{Marker Expression Profiles of Melanoma Cells Indicate High Heterogeneity within Cultures and Variability among Melanoma Specimens}

Melanoma cells were analyzed for marker expression profiles (Table 1). CD166 (ALCAM) and nestin were expressed in the vast majority of cells in melanospheres (DMBC2, DMBC8, and $\mathrm{DMBC} 10)$, cell aggregates (DMBC12), and single-cell population (DMBC9). Other markers were more diversely expressed. GD2 was present on almost all cells of tested populations, except for DMBC12. Expression of Oct3/4 also displayed variable pattern. The present results and those obtained previously ${ }^{23,25}$ revealed a high immunophenotypic heterogeneity within cell populations cultured in SCM and a remarkable variability among cultures derived from different NM specimens. As all populations exerted unlimited proliferative potential, but the cells expressing CD133, CD90, CD20, or Tra1-81 were undetectable in at least one of investigated populations, it could be speculated that this unlimited growth was not dependent on the presence of cells expressing any of those antigens.

\section{Expression of MITF and Tyrosinase but Not Cyclin D1 Correlates with Cell Capability of Forming Melanospheres}

MITF and the MITF-dependent gene TYR were expressed at markedly higher levels in the populations forming melanospheres (DMBC2, DMBC8, and $\mathrm{DMBC} 10)$ than in those grown as aggregates (DMBC12) or single-cell culture (DMBC9) (Figure 4). Interestingly, when melanospheres
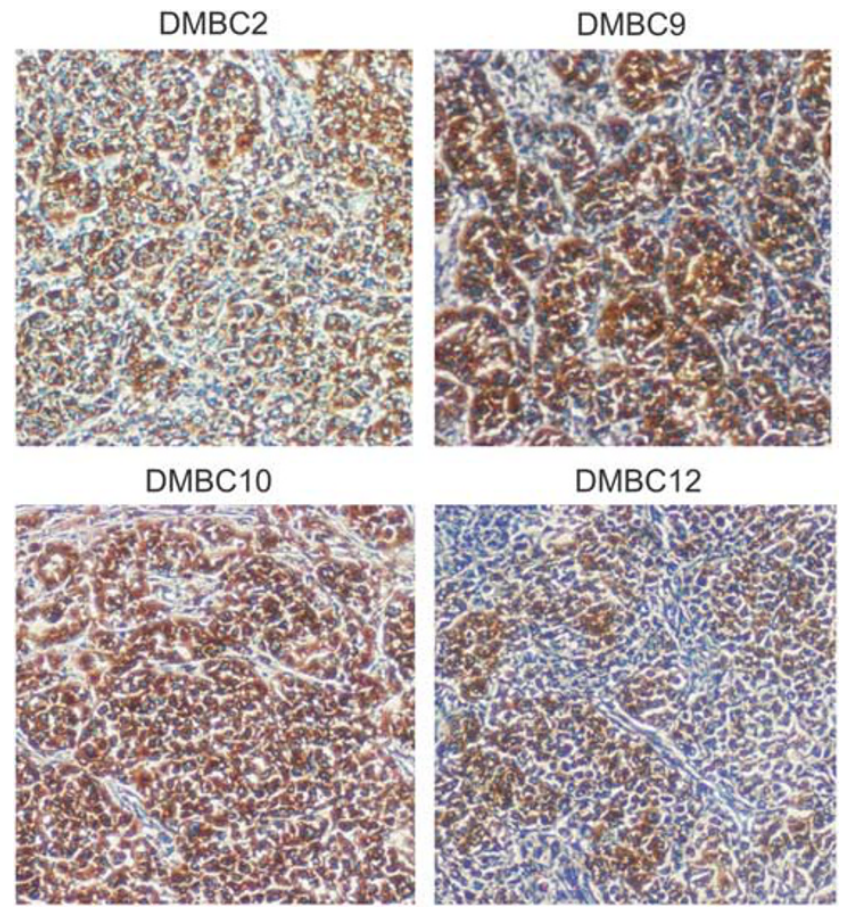

Figure 1 Cytoplasmic staining of FFPE sections of DMBC2, DMBC9, $\mathrm{DMBC} 10$, and DMBC12 melanoma samples for Melan-A (×200). 

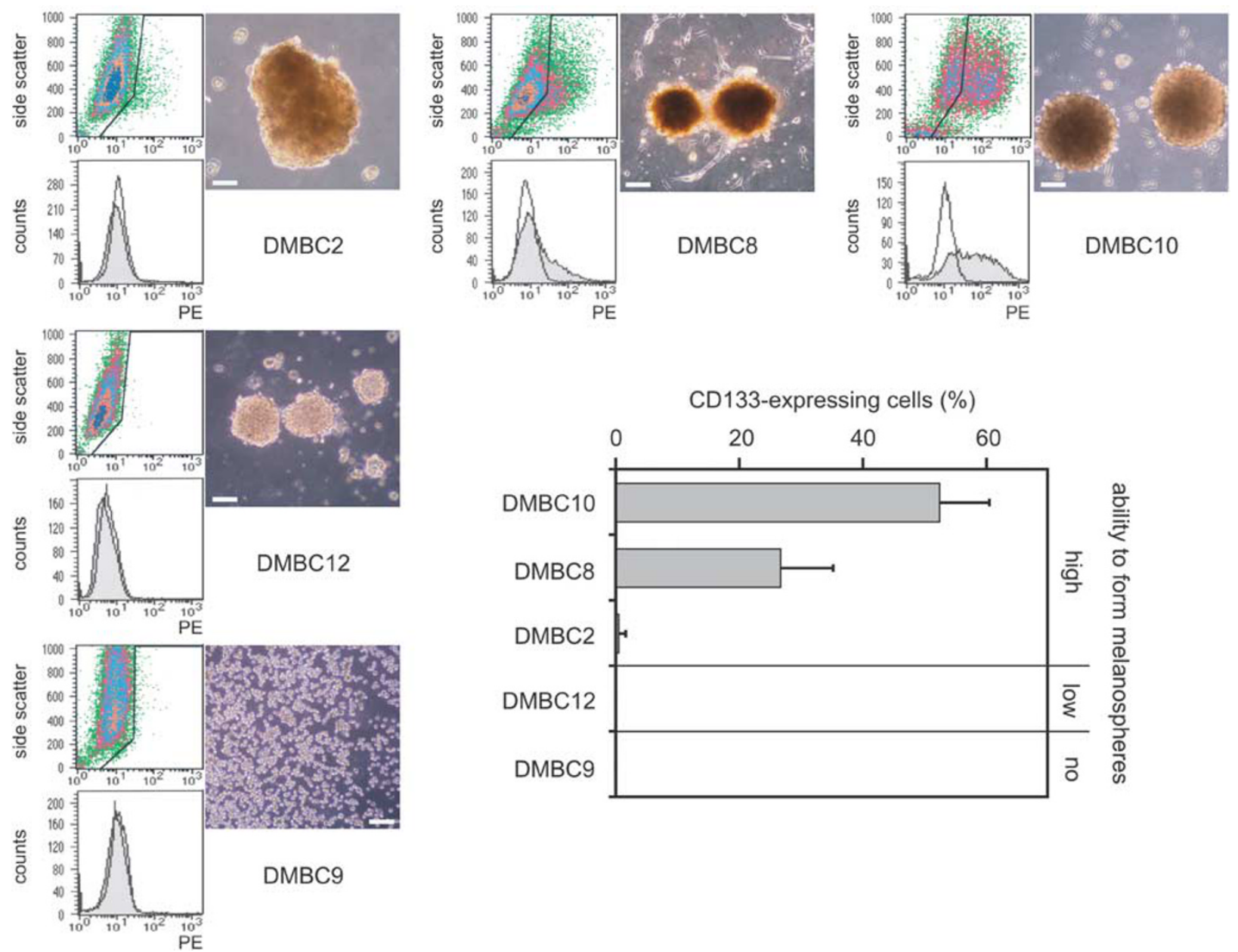

Figure 2 Patient-derived populations of nodular melanomas exhibited diverse morphology and frequency of CD133-positive cells. Representative phasecontrast microphotographs of melanoma cells cultured in SCM (scale bar, $100 \mu \mathrm{m}$ ) along with flow cytometric analysis of CD133 expression (solid lines, isotypematched control; shaded areas, cells expressing CD133). Graph illustrates the percentages of cells expressing CD133. Bars represent the mean \pm s.d. $(n=3)$.

were induced in the single-cell culture of DMBC9 by transient hypoxia-like conditions, expression of MITF and TYR was substantially increased to the level obtained for patientderived melanospheres (Figure 4). These results suggest that melanospheres, those directly derived from surgical specimens and those induced in culture by hypoxia-like conditions, are similar in respect to expression of MITF and TYR. The enormous alteration in expression of these genes during formation of melanospheres by DMBC9 suggests changes in the composition of subpopulations rather than increased MITF expression and activity in each cell. On the contrary, no substantial differences between diverse DMBC populations were found for the CCND1 expression that was assessed simultaneously (Figure 4).

\section{Differentiation Capacity of Cells Derived from Melanospheres}

In our previous study, when SCM was replaced with serumcontaining medium, transition from anchorage-independent melanospheres into adherent monolayers was observed. ${ }^{23}$ Similar morphological alterations were also observed without changes in growth conditions. With time, a substantial number of adherent cells appeared in cultures of melanospheres (DMBC2, DMBC8, and DMBC10), whereas cell aggregates (DMBC12) generated much less cells forming monolayers. This prompted us to examine differentiation status of melanosphere-derived monolayers. Staining with Oil Red $\mathrm{O}$ was used to visualize cells differentiated into adipocytes (Figure 5a). Adherent cells of DMBC2 and DMBC10 produced the most intense stains. Structures characteristic for vasculogenic differentiation were also visible, especially in DMBC8 culture, that on the other hand had a low frequency of adipocyte-like cells. We assessed the frequency of cells carrying the platelet-endothelial cell adhesion molecule (PECAM-1, CD31) and the endothelial cell marker von Willebrand Factor (vWF). Indeed, DMBC8 exerted the highest frequency of CD31-positive cells (Figure 5b). Those cells also had the highest level of vWF-positive cells 
Table 1 A variability in the frequency of cells expressing a given marker within populations derived from different melanoma specimens

\begin{tabular}{|c|c|c|c|c|c|c|c|c|c|c|}
\hline Melanoma population & CD133 & CD166 & GD2 & Nestin & CD34 & Oct3/4 & Melan-A & gp100 & CD20 & Tra-1-81 \\
\hline $\mathrm{DMBC2}$ & 0.2 & 78.9 & 65.7 & 93.5 & 9.1 & 39.0 & 69.0 & 60.0 & 0 & 0 \\
\hline \multirow[t]{2}{*}{$\mathrm{DMBC} 8$} & 36.4 & 73.7 & 83.6 & 94.0 & 8.4 & 55.0 & 79.7 & 55.0 & 0 & 0.3 \\
\hline & 22.4 & & 84.1 & 84.0 & 9.3 & 34.0 & 83.0 & 49.1 & & 0 \\
\hline \multirow[t]{2}{*}{ DMBC9 } & 0 & 86.0 & 99.0 & 86.0 & 9.7 & 63.0 & 48.0 & 74.0 & 0 & 0 \\
\hline & & & 90.0 & 99.0 & & & & 68.0 & & \\
\hline \multirow[t]{3}{*}{ DMBC10 } & 52.4 & 81.0 & 98.0 & 96.0 & 7.0 & 38.0 & 72.5 & 90.0 & 0 & 0 \\
\hline & 61.5 & & 85.2 & 98.5 & 16.0 & & 47.0 & 52.0 & & \\
\hline & 41.9 & & 91.0 & & 10.1 & & & & & \\
\hline
\end{tabular}

The frequencies of cells expressing indicated marker were assessed within the first 16 months of continuous culturing, but not earlier than after 3 months. In some cases results of two or three independent measurements are shown.
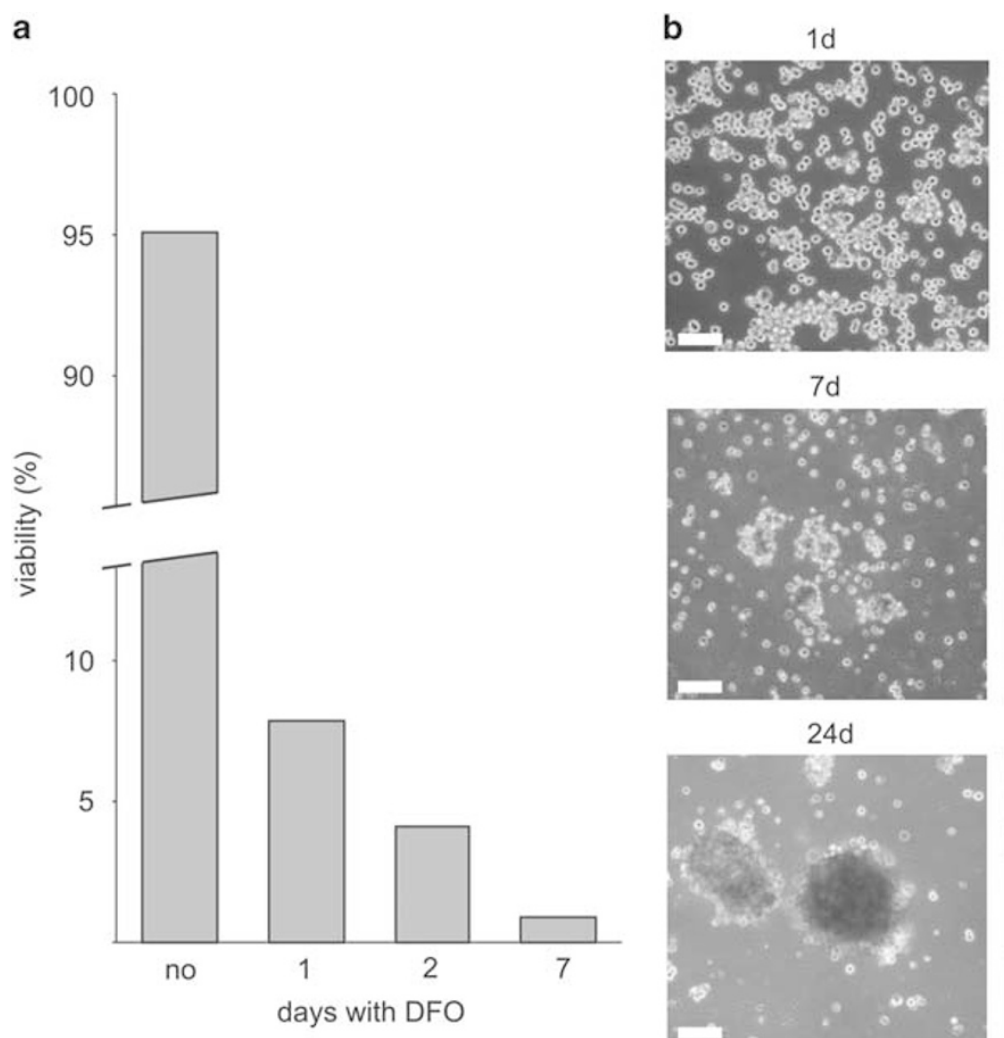

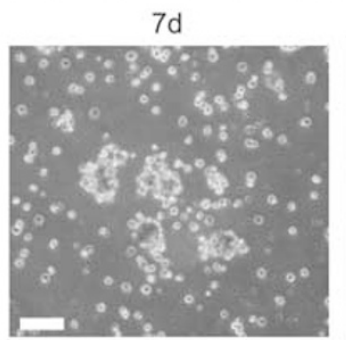

$24 d$

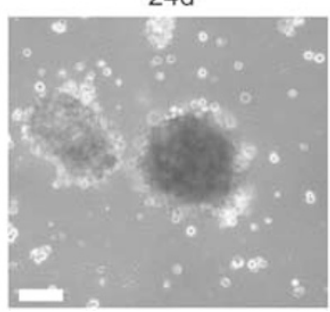

$11 \mathrm{~d}$

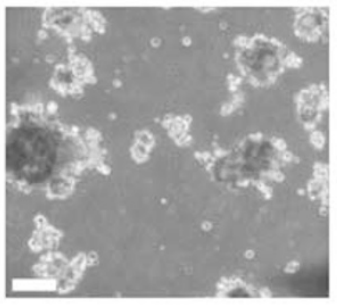

$34 \mathrm{~d}$

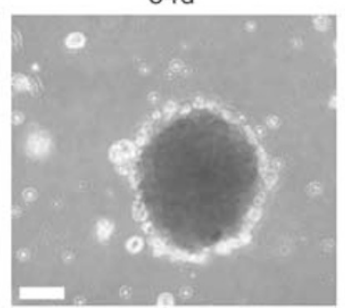

$17 d$

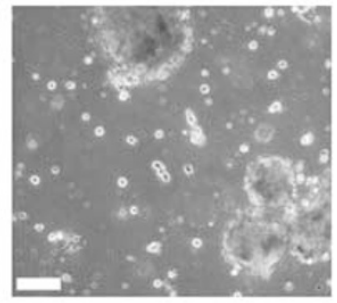

$44 d$

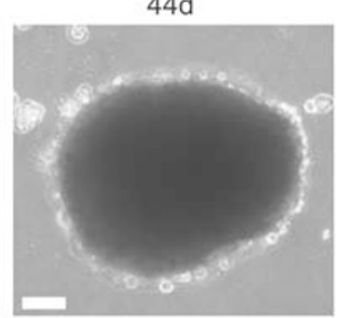

Figure 3 Melanospheres could be generated under transient hypoxia-like conditions from the single-cell culture of DMBC9. (a) Viability measured in DMBC9 population exposed to deferoxamine mesylate (DFO) for 1, 2, or 7 days. Percentages of viable cells were assessed after Trypan blue staining. (b) Representative phase-contrast microphotographs of melanospheres formed within 44-day period after 1 day of exposure to $100 \mu \mathrm{m}$ DFO (scale bar, $100 \mu \mathrm{m})$. 


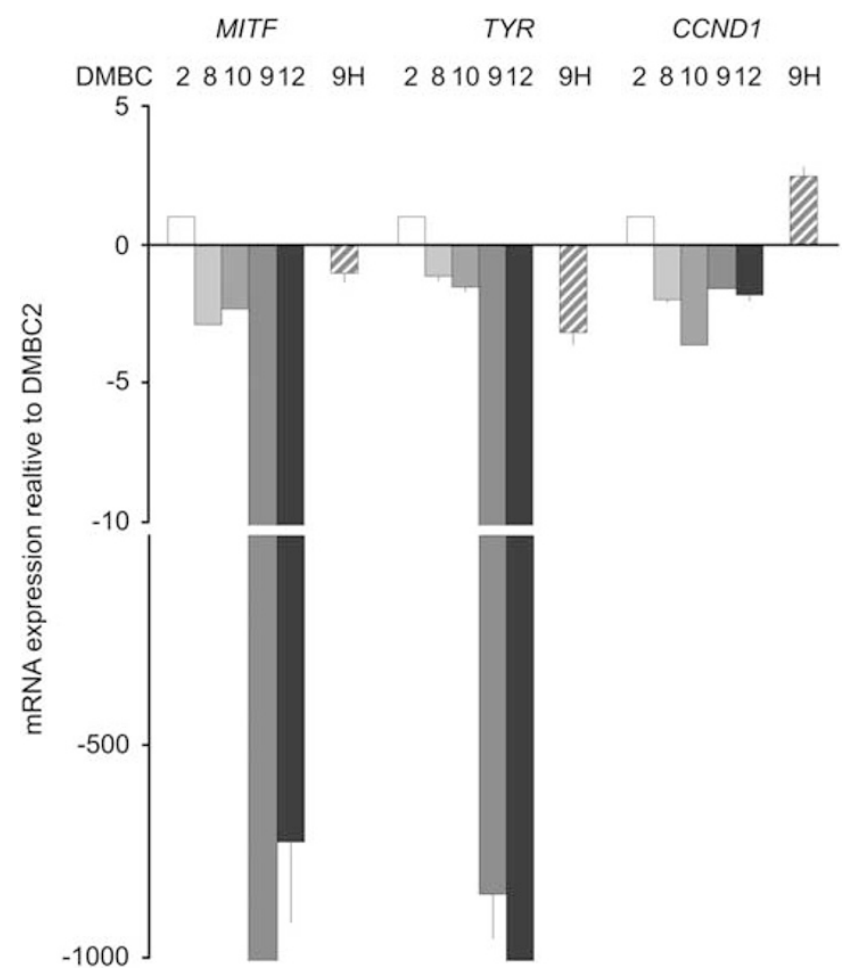

Figure 4 MITF and MITF-dependent gene TYR but not CCND1 were highly upregulated in melanospheres, both patient derived and hypoxia induced. Expression of genes was assessed using qRT-PCR. The expression level of each gene was normalized to the expression of a reference gene, RPS17. Data are presented as fold change in indicated population versus DMBC2 population, in which the expression levels of the genes were set as 1 . In addition, the gene expression in hypoxia-induced melanospheres $(9 \mathrm{H})$ is shown. The mean values and s.d. were calculated from two experiments performed in triplicates. A fold change of $>1000$ is shown as 1000 .
(8.3\%). In other populations, the frequencies of vWF-positive cells were between 1.3 and 5.6\% (not shown).

\section{Stability of Melanosphere Phenotype}

During continuous culturing, melanospheres formed by $\mathrm{DMBC}$, DMBC8, and DMBC10 populations were progressively substituted with less pigmented cell aggregates (Figure 6a). In an attempt to characterize the molecular mechanism by which melanoma cell populations lost their ability to form spheres, alterations in the immunophenotype and gene expression were assessed. The percentages of ABCB5-positive cells were stable and similar in the melanospheres and the aggregates in all tested populations (Figure 6b). The frequencies of gp100- and CD49f-positive cells, although changing from one experiment to another, were not significantly altered during transition from melanospheres into cell aggregates. On the contrary, the frequencies of cells carrying CD133, CD90, GD2, CD34, and Melan-A were progressively reduced (Figure 6b). MITF-dependent genes involved in the anti-apoptotic response and melanogenesis, except for DCT, were expressed at markedly lower levels in the aggregates when compared with the melanospheres (Figure 7a). This could be related to the loss of a subpopulation of more differentiated Melan-A-positive cells in aggregates (Figure 6b). When expression of components and targets of Wnt pathway was analyzed, the observed differences were more diverse with some genes upregulated in cell aggregates, such as PRDM1 or CCND1, whereas other genes, such as CTNNB1, downregulated when compared with the expression in the melanospheres (Figure 7b). However, the expression of Wnt pathway components was not so a

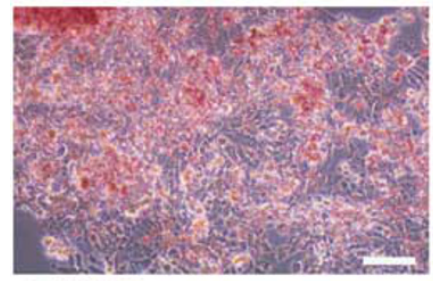

DMBC2

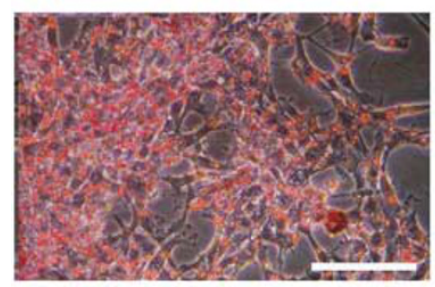

DMBC10

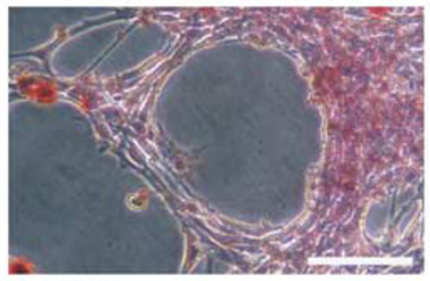

DMBC8

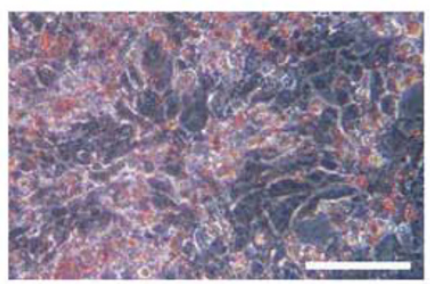

DMBC12 b

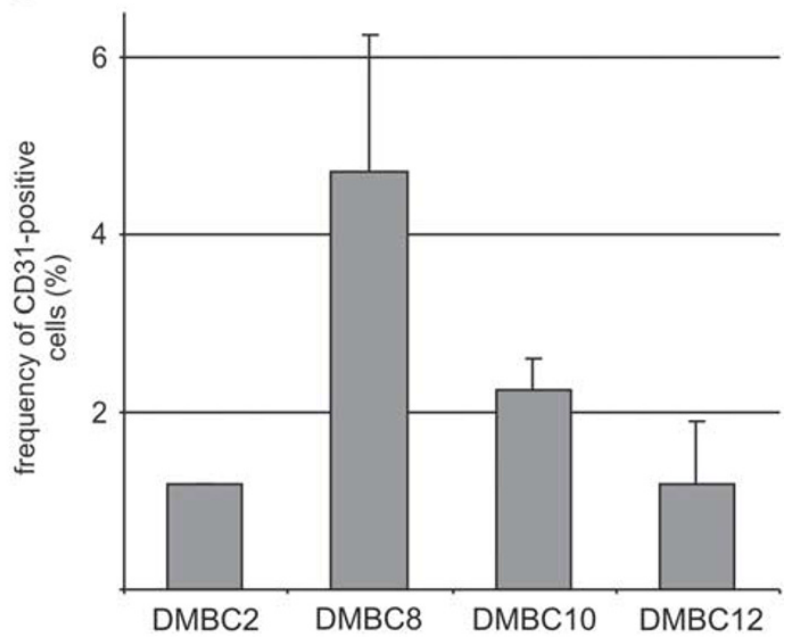

Figure 5 Adherent counterparts accompanying melanospheres and aggregates exhibited altered differentiation status. (a) Some of adherent cells showed positive staining with Oil Red $\mathrm{O}$, which indicated adipocyte-like phenotype, some formed structures, which suggested vasculogenic differentiation (scale bar, $100 \mu \mathrm{m}$ ). (b) The frequency of CD31-positive cells in monolayers was quantified by flow cytometry. 
a
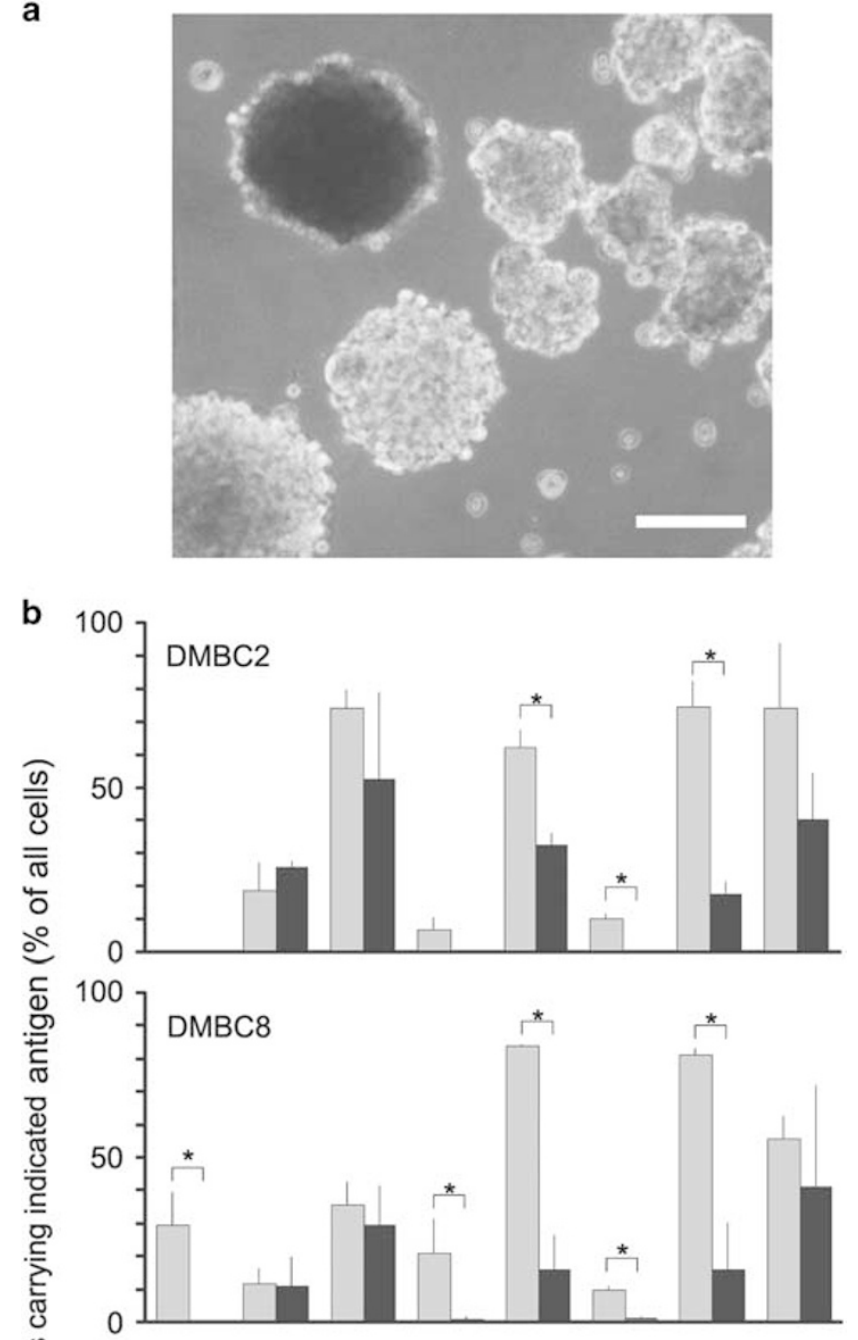

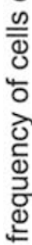

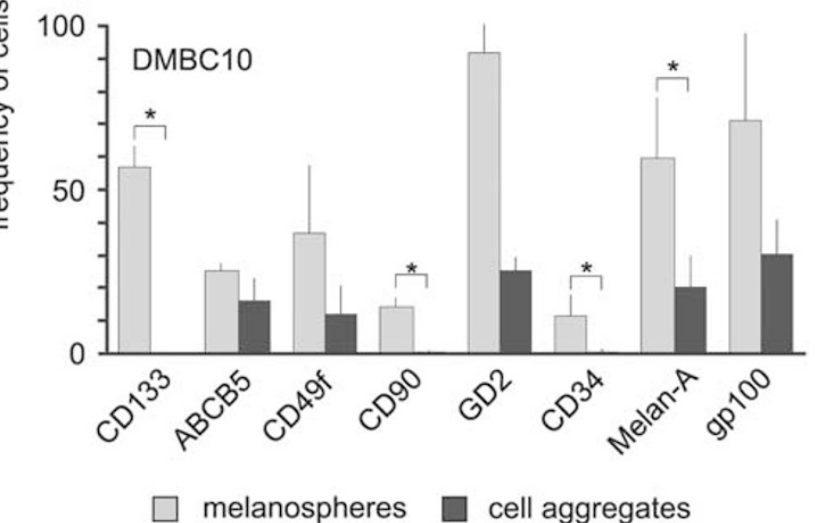

Figure 6 Melanoma phenotype was unstable during prolonged culturing. (a) Melanospheres were substituted with less pigmented cell aggregates. Phase-contrast microphotographs of melanoma cells cultured in SCM (scale bar, $100 \mu \mathrm{m}$ ). (b) Changes in immunophenotype were observed during transition from melanospheres into cell aggregates. The frequencies of cells carrying several markers were progressively reduced, whereas the percentage of ABCB5-positive cells was not markedly changed. strongly affected by long-term culturing as the expression of MITF-dependent genes.

As expression of MITF-dependent genes involved in melanogenesis was most dramatically reduced during transition from the melanospheres to the cell aggregates, we investigated well-established and broadly used cell lines A375, WM793B, and 1205Lu for comparison. When conditions promoting an anchorage-independent growth were used as for DMBC populations, both metastatic cell lines, A375 and $1205 \mathrm{Lu}$, did not form melanospheres but cell aggregates, whereas the primary melanoma cell line WM793B formed a monolayer (Figure 8a). The expression of Melan-A measured by flow cytometry was very low, almost undetectable (Figure 8b), and the level of transcripts for MITF and MITF-dependent genes TYR, MLANA, and BCL2A1 was much lower than in DMBC2 melanospheres used for comparison (Figure 8c). Only CCND1 was expressed at similar level as in DMBC2 melanospheres. Thus, results obtained for cell lines cultured in SCM were similar as for DMBC cell aggregates after transition from melanospheres: expression of genes involved in melanogenesis was markedly reduced, whereas other genes (eg, CCND1) were expressed at slightly higher levels.

\section{DISCUSSION}

Intratumoral heterogeneity is poorly understood at the molecular level. Melanoma cells are able to form spheres when cultured in SCM without serum..$^{23,27-34}$ Melanoma cells from spheres are more tumorigenic than adherent cells when grafted into NOD/SCID mice, ${ }^{27,29}$ and several reports including our own suggest that melanospheres well portray the parent tumor heterogeneity. ${ }^{24,29,35}$

We investigated anchorage-independent melanoma populations generated from NM surgical specimens. We have shown previously that patient-derived melanoma populations contain cells that possess self-renewing capacity, a defining feature of cancer stem cells. Our present study reveals few new insights. First, patient-derived melanoma populations are capable of growing continuously in SCM for $>2$ years, thus exhibiting unlimited proliferative potential under these conditions. Second, among five patient-derived populations, no common immunophenotype was found and the frequencies of cells carrying particular markers, including those considered as CSC markers (eg, CD133), vary between patients. Third, melanoma populations, especially melanospheres, showed plasticity exhibited as changes in gene expression followed by phenotypic alterations, including the capability of differentiation into different lineages. Fourth, only melanospheres among anchorage-independent populations contain a subpopulation expressing MITF at high level, accompanied by upregulation of tyrosinase and strong pigmentation. Fifth, melanospheres progressively lost their potential to generate several of subpopulations from which they primarily consisted of, especially that one characterized by high expression of genes involved in melanogenesis. Sixth, 

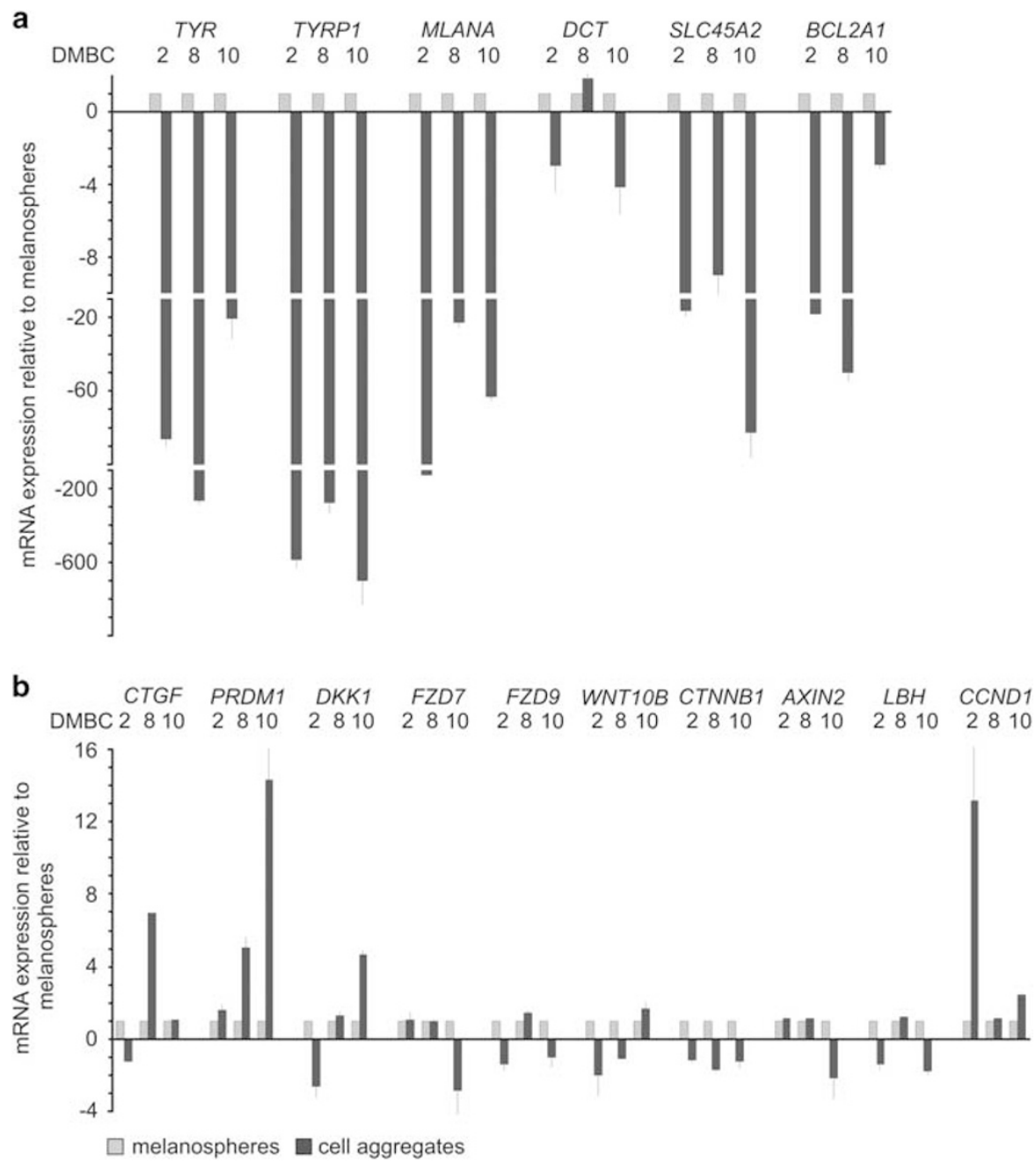

Figure 7 The expression of selected genes was substantially changed during transition from melanospheres into cell aggregates caused by prolonged culturing in SCM. (a) The qRT-PCR validation of the expression of selected MITF-dependent genes. (b) The qRT-PCR validation of selected Wnt pathway components or their regulators. The expression level of each gene was normalized to the expression of a reference gene, RPS17. Data are presented as fold change in cell aggregates versus original melanospheres, in which the expression levels of the genes were set as 1 . The mean values and s.d. were calculated from at least two experiments performed in triplicate.

the partial loss of heterogeneity during transition from melanospheres to cell aggregates does not reduce, however, the proliferative potential of melanoma cells and the frequency of ABCB5-positive cells.

We investigated a few markers previously considered as stem cell markers or melanoma-associated antigens, and conducted our study in populations of melanoma cells derived from surgical specimens and cultured in a xeno-free environment without any selection procedure. For many markers including CD133, Oct3/4, gp100, and Melan-A, an extensive phenotypic diversity was observed between populations derived from different specimens. Therefore, the present results and those obtained previously ${ }^{14,15,23,25}$ suggest that the marker expression profile seems to be an intrinsic characteristics of a particular melanoma sample. No correlation between the frequency of cells expressing a given marker and the capability of forming melanospheres was found. Although in three out of five investigated populations both expression of CD133 and formation of melanospheres were observed, this correlation was not confirmed in a gain-offunction experiment in which formation of melanospheres from the single-cell culture containing exclusively CD133negative cells was not accompanied by the appearance of CD133-positive cells. CD133 is one of the most frequently studied CSC markers. ${ }^{5,36-40}$ Compared with nevi, both primary and metastatic melanomas showed increased expression of CD133, ${ }^{41,42}$ and downregulation of CD133 resulted in reduced melanoma growth and ability to metastasize. ${ }^{43}$ It was reported that CD133-positive cells in melanoma biopsies had enhanced tumorigenic potential, ${ }^{9}$ and cells expressing CD133 in spheres exerted high clonogenic and tumorigenic potential. ${ }^{44}$ However, it was also found that CD133 could 
a

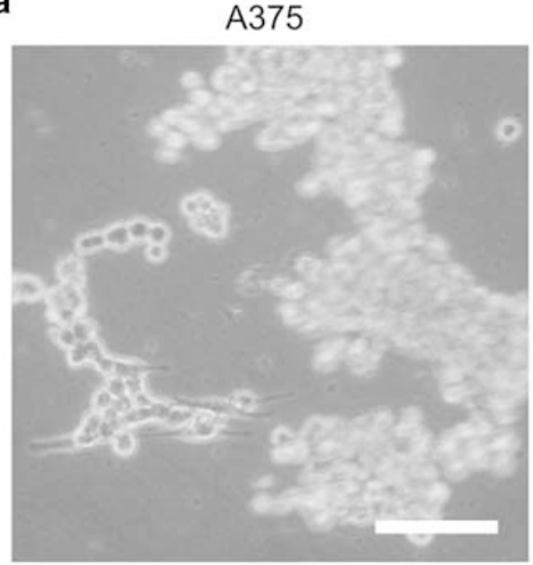

WM793B

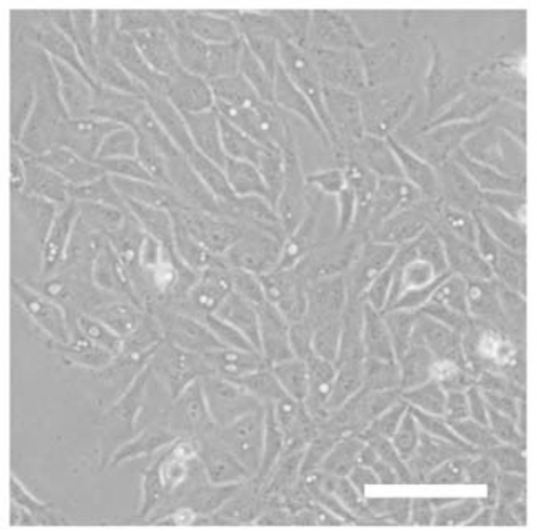

WM793B
1205Lu

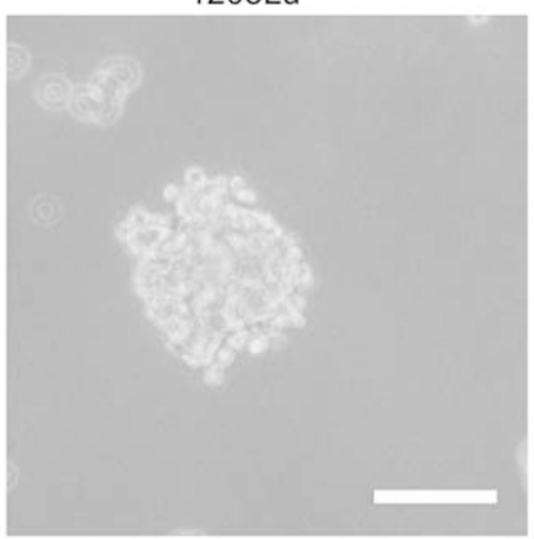

1205Lu

b

A375

$4.9 \%$

isotype

$1.5 \%$

isotype

$1.4 \%$
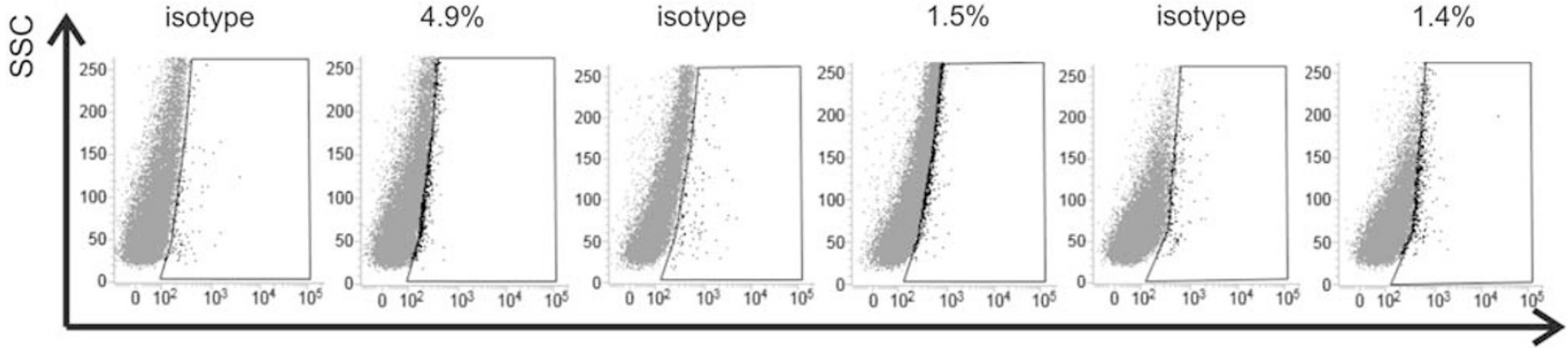

Melan-A

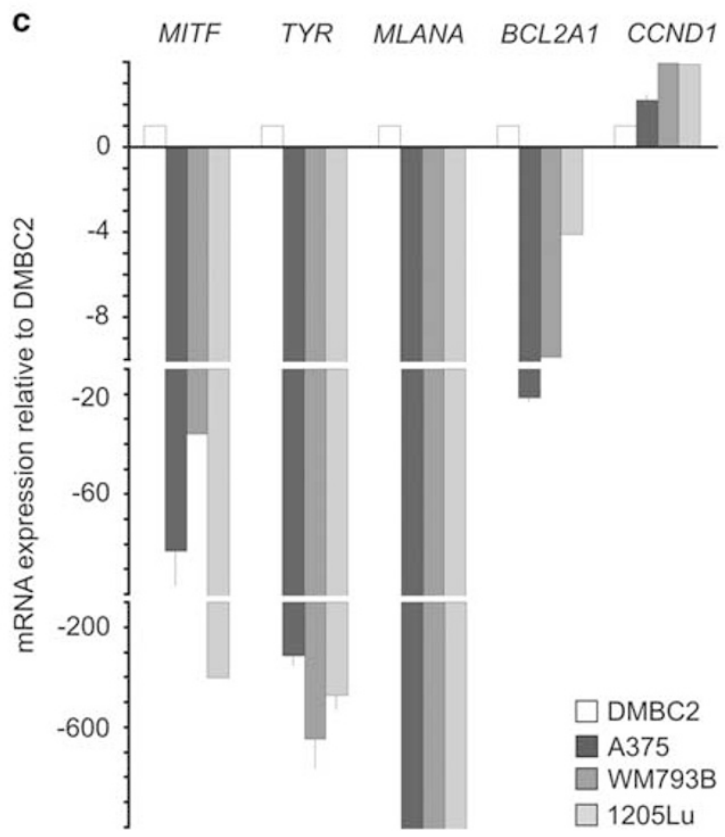

Figure 8 Characteristics of melanoma cell lines (A375, WM793B, and 1205Lu) under conditions suitable for an anchorage-independent growth. (a) Representative phase-contrast microphotographs of melanoma cell lines cultured in SCM. A375 cells and 1205Lu formed cell aggregates, whereas WM793B formed the monolayer (scale bar, $100 \mu \mathrm{m}$ ). (b) Flow cytometric analysis of Melan-A/MART-1 expression including isotype-matched control. Average percentages of Melan-A-positive cells from two independent experiments are shown. (c) Expression of MITF and MITF-dependent genes TYR, MLANA, and BCL2A1 but not CCND1 was much lower in melanoma cell lines than in patient-derived melanospheres. Expression of genes was assessed using qRT-PCR. The expression level of each gene was normalized to the expression of a reference gene, RPS17. Data are presented as fold change in the indicated population versus DMBC2 melanospheres, in which the expression levels of the genes were set as 1. The mean values and s.d. were calculated from two experiments performed in triplicates. A fold change of $>1000$ is shown as 1000 . 
be reversibly expressed by tumorigenic melanoma cells, ${ }^{45}$ and DMBC12 population that exhibited the highest self-renewing capacity in our previous report ${ }^{23}$ did not express CD133 at all. Only ABCB5 was expressed in all populations with frequencies close to the percentages of cells exerting the self-renewing capacity, ${ }^{23}$ and interestingly at the similar frequency as seen previously in patient samples. ${ }^{10}$ Thus, our results support the notion that ABCB5 could be considered as biomarker of melanoma stem-like cells. ${ }^{8,10,25,46,47}$ Moreover, both the colony-forming capacity (not shown) and frequency of ABCB5-positive cells remained unaffected during transition from melanospheres to cell aggregates. This might indicate that this subpopulation of melanoma cells exhibiting cancer stem cell properties was present in all forms of cultures and was stable during prolonged culturing.

Our present study has shown that melanospheres, those derived directly from melanoma specimens and those induced by hypoxia from single anchorage-independent cells, exhibit high expression and activity of MITF. This was exemplified by the increased expression of TYR, a gene encoding tyrosinase involved in melanogenesis. The enhanced TYR expression was accompanied with strong pigmentation. MITF is an important transcription factor for melanoma development and it is considered as being involved in melanoma phenotypic plasticity. ${ }^{48,49}$ High activity of MITF promotes differentiation, low activity is attributed to the stem cell-like and invasive phenotype, and prolonged MITF depletion causes melanoma cell senescence. MITF level varies between melanoma specimens ${ }^{50}$ and its expression is also dynamically regulated by the microenvironment. ${ }^{24,48,51,52}$ Recently, using a microarray analysis we demonstrated the enhanced activity of MITF in melanospheres grown in SCM in comparison with monolayers grown in serum-containing medium that was illustrated by increased expression of 74 MITF-dependent genes. ${ }^{24}$ Moreover, we have shown that expression of several genes in the melanospheres of $\mathrm{DMBC} 2, \mathrm{DMBC}$, and DMBC10 was similar as in the parent tumors. ${ }^{24}$ The present results showing the difference in MITF/TYR expression between populations forming and not forming melanospheres in SCM extended this observation and suggest the correlation between the architecture of the melanoma population and expression of MITF. In the previous studies, patient-derived melanoma spheres were shown to be either pigmented or nonpigmented, ${ }^{27,53}$ but MITF expression was not assessed. It is interesting that MITF-high melanosphere-forming subpopulation could be raised from MITF-low single-cell culture of DMBC9 population by using transient hypoxia-like conditions. Recent reports indicate that MITF and associated genes are repressed by hypoxia. ${ }^{54,55}$ HIF $1 \alpha$ is, however, not sufficient to inhibit the activity of the MITF promoter and the effect of HIF $1 \alpha$ on MITF is rather indirect, ${ }^{55}$ probably by the recruitment of DEC1 (Bhlhb2) to the MITF promoter. ${ }^{54}$ As HIF $1 \alpha$ was also recognized as a MITF $\operatorname{target}^{56}$ and is expressed in melanoma cells also under normoxic conditions, ${ }^{57,58}$ this mechanism constitutes an interesting negative feedback loop involved in the regulation of MITF expression. ${ }^{59}$ In our long-term experiments, MITF level and activity were increased many weeks after DFO was removed and HIF $\alpha$ expression was already at the level as before treatment, whereas HIF2 $\alpha$ was only slightly (twofold) increased (not shown).

Our present study and previous reports ${ }^{23,24}$ indicate that populations of melanoma cells capable of forming melanospheres exhibit a multi-subpopulation organization and broad functional diversity. In addition, the high plasticity of melanoma cells was observed as: (1) the percentage of cells expressing MITF and tyrosinase during hypoxia-induced transition from the single-cell culture to melanospheres was substantially raised, and (2) melanoma cells underwent differentiation into adipocyte-like and endothelial-like phenotype. Oil Red O staining confirmed adipogenic phenotype of some adherent cells present in the melanosphere cultures. Adipocytes were shown to be generated in melanoma cultures in adipogenic medium, ${ }^{27}$ and on the other hand adipogenesis could be enhanced by conditioned media obtained from cancer cells. ${ }^{60}$ Adipocytes that were previously considered as an energy storage depot were recently recognized as cells potentially modifying cancer cell phenotype leading to more aggressive behavior. ${ }^{61}$ How adipocyte-like cells derived from melanospheres might contribute to melanoma survival needs to be investigated. In addition, staining for CD31 and vWF suggests transdifferentiation of melanoma cells into a more endothelial-like phenotype. The ability of cancer cells to adopt this phenotype was described in melanoma ${ }^{62}$ and other cancer types such as Merkel cell carcinoma, lymphoma, neuroblastoma, and glioblastoma. ${ }^{63-66}$ Recently, melanoma spheroid formation was reported to involve vascular mimicry associated with laminin expression. ${ }^{67}$ Our microarray data analyses revealed increased expression of different laminin chains in melanospheres $v s$ monolayers (unpublished results, available at http://www.ebi.ac.uk/arrayexpress/ under the accession number E-MTAB-1869). The melanosphereassociated gene expression signature also included increased expression of VEGF isoforms encoded by VEGF-A and VEGF$B .^{24}$ It is unclear, however, which factor caused the switch from three-dimensional architecture to monolayer in SCM, and why different cell types are dominant in adherent populations from melanospheres derived from different patients. Certainly, any of previously defined microenvironmental insults, ${ }^{68}$ including nutrient fluctuations, hypoxia, and acidity, might contribute to these phenomena. Most recently, reciprocal paracrine interactions between different subpopulations of melanoma has been demonstrated as being involved in CSC maintenance. ${ }^{47}$ The mechanisms driving intratumoral variation in cellular function have to be elucidated. ${ }^{6}$ As MITF can be expressed at different levels in distinct subpopulations of the heterogeneous tumor mass, ${ }^{69}$ it would be interesting to elucidate how a MITF-enriched subpopulation can interplay with other subpopulations present in heterogeneous 
melanoma to support the growth and maintenance of the tumor, and whether this networking function is clinically relevant.

MITF expression and activity in melanoma cells from established cell lines A375, WM793B, and 1205Lu grown in SCM were very low, similarly as in many other cell lines investigated previously in serum-containing medium..$^{70,71}$ This might indicate that culturing cells in SCM is not sufficient to change the MITF level. Moreover, none of these cell lines formed melanospheres in SCM. There are no data demonstrating whether originally, before cell lines were established, WM793B, 1205Lu, and A375 cells formed melanospheres in SCM (as DMBC2, DMBC8, and DMBC10) or cell aggregates (as DMBC12), and whether they expressed MITF at a high level. Our present results suggest that some changes that appeared with time in culture might be irreversible and MITF is a critical transcription factor in preserving the phenotypic heterogeneity of tumor. Therefore, patient-derived melanoma populations should be considered as more suitable for the study of melanoma biology than established melanoma cell lines used in culture for decades.

When therapeutic targeting is considered, melanospheres as heterogeneous populations that mirror to some extent the parent tumors might be more relevant for drug testing than more homogeneous monolayers or any selected subpopulation. In our recent study re-evaluating activities of 120 compounds from The Natural Products Set II in nodular and superficial spreading melanoma populations grown in SCM, we selected compounds with activity against fast-cycling cells but also against slow-cycling cells, potentially with stem cell characteristics. $^{72}$

In summary, even if melanoma cells derived from different specimens were cultured under the same conditions, they exhibited diverse morphology, immunophenotype, gene expression, plasticity, and capacity to self-renew. Melanospheres represent a noteworthy model for studying the biology of melanoma as they exhibit higher plasticity and heterogeneity than other anchorage-independent cultures. The reasons why melanospheres are formed only by some patient-derived samples and why they are progressively substituted with less heterogeneous cell aggregates are unclear and need further investigation. Modeling disease 'in a dish' using patient-derived cells is increasingly being used. The most spectacular development is observed in technology employing induced pluripotent stem cells (iPSCs) for pathobiology studies. ${ }^{73}$ In case of cancer, it becomes more clear that the real progress will be achieved when the original heterogeneity of patient sample is preserved in vitro but many issues remain to be improved and the limitations are still not well recognized.

\section{ACKNOWLEDGMENTS}

We thank Professor Markus Duechler for reviewing the manuscript, Professor Ewa Zuba-Surma for her help in initial experiments employing flow cytometry, Professor Marian Danilewicz for sharing his expertise in IHC, and Karolina
Niewinna for excellent technical assistance. Research was supported by Grant 2011/01/B/NZ4/04921 from the National Science Centre. The content is solely the responsibility of the authors.

\section{DISCLOSURE/CONFLICT OF INTEREST}

The authors declare no conflict of interest.

1. Girouard SD, Murphy GF. Melanoma stem cells: not rare, but well done. Lab Invest 2011;91:647-664.

2. Singh SR. Cancer stem cells: recent developments and future prospects. Cancer Lett 2013;338:1-2.

3. O'Connor ML, Xiang D, Shigdar S et al. Cancer stem cells: a contentious hypothesis now moving forward. Cancer Lett 2014;344:180-187.

4. Lee N, Barthel SR, Schatton T. Melanoma stem cells and metastasis: mimicking hematopoietic cell trafficking? Lab Invest 2014;94:13-30.

5. Pattabiraman DR, Weinberg RA. Tackling the cancer stem cells - what challenges do they pose? Nat Rev Drug Discov 2014;13:497-512.

6. Kreso A, Dick JE. Evolution of the cancer stem cell model. Cell Stem Cell 2014;14:275-291.

7. Strizzi L, Hardy KM, Kirsammer GT et al. Embryonic signaling in melanoma: potential for diagnosis and therapy. Lab Invest 2011;91: 819-824.

8. Frank NY, Margaryan A, Huang $Y$ et al. ABCB5-mediated doxorubicin transport and chemoresistance in human malignant melanoma. Cancer Res 2005;65:4320-4333.

9. Monzani E, Facchetti F, Galmozzi E et al. Melanoma contains CD133 and ABCG2 positive cells with enhanced tumourigenic potential. Eur J Cancer 2007;43:935-946.

10. Schatton T, Murphy GF, Frank NY et al. Identification of cells initiating human melanomas. Nature 2008;451:345-349.

11. Boiko $A D$, Razorenova OV, van de Rijn $M$ et al. Human melanomainitiating cells express neural crest nerve growth factor receptor CD271. Nature 2010;466:133-137.

12. Boonyaratanakornkit JB, Yue L, Strachan LR et al. Selection of tumorigenic melanoma cells using ALDH. J Invest Dermatol 2010;130: 2799-2808.

13. Civenni $\mathrm{G}$, Walter $\mathrm{A}$, Kobert $\mathrm{N}$ et al. Human CD271-positive melanoma stem cells associated with metastasis establish tumour heterogeneity and long-term growth. Cancer Res 2011;71:3098-3109.

14. Quintana E, Shackleton M, Foster HR et al. Phenotypic heterogeneity among tumourigenic melanoma cells from patients that is reversible and not hierarchically organized. Cancer Cell 2010;18:510-523.

15. Quintana E, Shackleton M, Sabel MS et al. Efficient tumour formation by single human melanoma cells. Nature 2008;456:593-598.

16. Kopetz S, Lemos R, Powis G. The promise of patient-derived xenografts: the best laid plans of mice and men. Clin Cancer Res 2012;18:5160-5162.

17. Malaney $P$, Nicosia SV, Davé V. One mouse, one patient paradigm: new avatars of personalized cancer therapy. Cancer Lett 2014;344:1-12.

18. Williams SA, Anderson WC, Santaguida MT et al. Patient-derived xenografts, the cancer stem cell paradigm, and cancer pathobiology in the 21st century. Lab Invest 2013;93:970-982.

19. Sachs N, Clevers H. Organoid cultures for the analysis of cancer phenotypes. Curr Opin Genet Dev 2014;24:68-73.

20. Lee J, Kotliarova $S$, Kotliarov $Y$ et al. Tumor stem cells derived from glioblastomas cultured in bFGF and EGF more closely mirror the phenotype and genotype of primary tumors than do serum-cultured cell lines. Cancer Cell 2006;9:391-403.

21. Morrison BJ, Steel JC, Morris JC. Sphere culture of murine lung cancer cell lines are enriched with cancer initiating cells. PLoS One 2012;7: e49752.

22. Hirschhaeuser F, Menne $\mathrm{H}$, Dittfeld $\mathrm{C}$ et al. Multicellular tumor spheroids: an underestimated tool is catching up again. J Biotechnol 2010;148:3-15.

23. Sztiller-Sikorska M, Koprowska K, Jakubowska J et al. Sphere formation and self-renewal capacity of melanoma cells is affected by the microenvironment. Melanoma Res 2012;22:215-224.

24. Hartman ML, Talar B, Noman MZ et al. Gene expression profiling identifies microphthalmia-associated transcription factor (MITF) and Dickkopf-1 (DKK1) as regulators of microenvironment-driven alterations in melanoma phenotype. PLoS One 2014;9:e95157. 
25. Czyz M, Koprowska K, Sztiller-Sikorska M. Parthenolide reduces the frequency of $A B C B 5$-positive cells and clonogenic capacity of melanoma cells from anchorage independent melanospheres. Cancer Biol Ther 2013;14:135-145.

26. Koprowska K, Hartman ML, Sztiller-Sikorska $M$ et al. Parthenolide enhances dacarbazine activity against melanoma cells. Anticancer Drugs 2013;24:835-845.

27. Fang D, Nguyen TK, Leishear K et al. A tumourigenic subpopulation with stem cell properties in melanomas. Cancer Res 2005;65:9328-9337.

28. Keshet $\mathrm{Gl}$, Goldstein I, Itzhaki O et al. MDR1 expression identifies human melanoma stem cells. Biochem Biophys Res Commun 2008:368:930-936.

29. Perego $M$, Tortoreto $M$, Tragni $G$ et al. Heterogeneous phenotype of human melanoma cells with in vitro and in vivo features of tumourinitiating cells. J Invest Dermatol 2010;130:1877-1886.

30. Rappa G, Mercapide J, Anzanello F et al. Growth of cancer cell lines under stem cell-like conditions has the potential to unveil therapeutic targets. Exp Cell Res 2008;314:2110-2122.

31. Ramgolam K, Lauriol J, Lalou C et al. Melanoma spheroids grown under neural crest cell conditions are highly plastic migratory/invasive tumour cells endowed with immunomodulator function. PLoS One 2011;6:e18784.

32. Ghislin S, Deshayes F, Lauriol J et al. Plasticity of melanoma cells induced by neural cell crest conditions and three-dimensional growth Melanoma Res 2012;22:184-194.

33. Sette G, Fecchi K, Salvati $V$ et al. Mek inhibition results in marked antitumor activity against metastatic melanoma patient-derived melanospheres and in melanosphere-generated xenografts. J Exp Clin Cancer Res 2013;32:91.

34. Roesch A, Fukunaga-Kalabis M, Schmidt EC et al. A temporarily distinct subpopulation of slow-cycling melanoma cells is required for continuous tumour growth. Cell 2010;141:583-594.

35. Thurber AE, Douglas G, Sturm EC et al. Inverse expression states of the BRN2 and MITF transcription factors in melanoma spheres and tumour xenografts regulate the NOTCH pathway. Oncogene 2011;30:3036-3048.

36. Bidlingmaier $\mathrm{S}$, Zhu $\mathrm{X}$, Liu B. The utility and limitations of glycosylated human CD133 epitopes in defining cancer stem cells. J Mol Med 2008;86:1025-1032.

37. Tirino V, Desiderio V, d'Aquino $\mathrm{R}$ et al. Detection and characterization of CD133+ cancer stem cells in human solid tumours. PLoS One 2008;3:e3469.

38. Fang DD, Kim YJ, Lee CN et al. Expansion of CD133(+) colon cancer cultures retaining stem cell properties to enable cancer stem cell target discovery. Br J Cancer 2010;102:1265-1275.

39. Chao C, Carmical JR, Ives KL et al. CD133+ colon cancer cells are more interactive with the tumor microenvironment than CD133- cells. Lab Invest 2012;92:420-436.

40. Peickert S, Waurig J, Dittfeld C et al. Rapid re-expression of CD133 protein in colorectal cancer cell lines in vitro and in vivo. Lab Invest 2012;92:1607-1622

41. Klein WM, Wu BP, Zhao $S$ et al. Increased expression of stem cell markers in malignant melanoma. Mod Pathol 2007;20:102-107.

42. Sharma BK, Manglik V, Elias EG. Immuno-expression of human melanoma stem cell markers in tissue at different stages of the disease. J Surg Res 2010;163:e11-e15.

43. Rappa G, Fodstad O, Lorico A. The stem cell-associated antigen CD133 (Prominin-1) is a molecular therapeutic target for metastatic melanoma. Stem Cells 2008;26:3008-3017.

44. Zimmerer RM, Korn P, Demougin $\mathrm{P}$ et al. Functional features of cancer stem cells in melanoma cell lines. Cancer Cell Int 2013;13:78.

45. Shackleton M, Quintana E, Fearon ER et al. Heterogeneity in cancer: cancer stem cells versus clonal evolution. Cell 2009;138:822-829.

46. Ma J, Lin JY, Alloo A et al. Isolation of tumorigenic circulating melanoma cells. Biochem Biophys Res Commun 2010;402:711-717.

47. Wilson BJ, Saab KR, Ma J et al. ABCB5 maintains melanoma-initiating cells through a proinflammatory cytokine signaling circuit. Cancer Res 2014;74:4196-4207.

48. Bell RE, Levy C. The three M's: melanoma, microphthalmia-associated transcription factor and microRNA. Pigment Cell Melanoma Res 2011;24:1088-1106.
49. Hartman ML, Czyz M. Pro-survival role of MITF in melanoma. J Invest Dermatol 2015;135:352-358.

50. Flaherty KT, Hodi FS, Fisher DE. From genes to drugs: targeted strategies for melanoma. Nat Rev Cancer 2012;12:349-361.

51. Hoek KS, Goding CR. Cancer stem cells versus phenotype-switching in melanoma. Pigment Cell Melanoma Res 2010;23:746-759.

52. Bell RE, Khaled M, Netanely $D$ et al. Transcription factor/microRNA axis blocks melanoma invasion program by miR-211 targeting NUAK1. Invest Dermatol 2014;134:441-451.

53. Mo J, Sun B, Zhao X et al. The in vitro spheroid culture induces a more highly differentiated but tumorigenic population from melanoma cell lines. Melanoma Res 2013;23:254-263.

54. Feige E, Yokoyama S, Levy $C$ et al. Hypoxia-mediated transcriptional repression of the melanoma-associated oncogene MITF. Proc Nat Acad Sci USA 2011;108:E924-E933.

55. Cheli $\mathrm{Y}$, Giuliano S, Fenouille $\mathrm{N}$ et al. Hypoxia and MITF control metastatic behaviour in mouse and human melanoma cells. Oncogene 2012;31:2461-2470.

56. Busca R, Berra E, Gaggioli C et al. Hypoxia-inducible factor $1 a$ is a new target of microphthalmia-associated transcription factor (MITF) in melanoma cells. J Cell Biol 2005;170:49-59.

57. Mills CN, Joshi SS, Niles RM. Expression and function of hypoxia inducible factor- 1 alpha in human melanoma under non-hypoxic conditions. Mol Cancer 2009;8:104.

58. Kuphal S, Winklmeier A, Warnecke $\mathrm{C}$ et al. Constitutive HIF-1 activity in malignant melanoma. Eur J Cancer 2010;46:1159-1169.

59. Hartman ML, Czyz M. MITF in melanoma: mechanisms behind its expression and activity. Cell Mol Life Sci 2015;72:1249-1260.

60. Hirano $\mathrm{T}$, Morii $\mathrm{H}$, Nakazawa $\mathrm{K}$ et al. Enhancement of adipogenesis induction by conditioned media obtained from cancer cells. Cancer Lett 2008;268:286-294.

61. Dirat B, Bochet $L$, Dabek $M$ et al. Cancer-associated adipocytes exhibit an activated phenotype and contribute to breast cancer invasion. Cancer Res 2011;71:2455-2465.

62. Hendrix MJ, Seftor EA, Hess AR et al. Vasculogenic mimicry and tumour-cell plasticity: lessons from melanoma. Nat Rev Cancer 2003;3 411-421.

63. Lezcano $\mathrm{C}$, Kleffel $\mathrm{S}$, Lee $\mathrm{N}$ et al. Merkel cell carcinoma expresses vasculogenic mimicry: demonstration in patients and experimental manipulation in xenografts. Lab Invest 2014;94:1092-1102.

64. Streubel B, Chott A, Huber D et al. Lymphoma-specific genetic aberrations in microvascular endothelial cells in B-cell lymphomas. N Engl J Med 2004;351:250-259.

65. Pezzolo A, Parodi F, Corrias MV et al. Tumour origin of endothelial cells in human neuroblastoma. J Clin Oncol 2007;25:376-383.

66. Ricci-Vitiani $L$, Pallini $R$, Biffoni $M$ et al. Tumour vascularization via endothelial differentiation of glioblastoma stem-like cells. Nature 2010; 468:824-828.

67. Larson AR, Lee CW, Lezcano $C$ et al. Melanoma spheroid formation involves laminin-associated vasculogenic mimicry. Am J Pathol 2014; 184:71-78.

68. Taddei ML, Giannoni E, Comito G et al. Microenvironment and tumor cell plasticity: an easy way out. Cancer Lett 2013;341: 80-96.

69. Somasundaram R, Villanueva J, Herlyn M. Intratumoral heterogeneity as a therapy resistance mechanism: role of melanoma subpopulations. Adv Pharmacol 2012;65:335-359.

70. Kono M, Dunn IS, Durda PJ et al. Role of the mitogen-activated protein kinase signaling pathway in the regulation of human melanocytic antigen expression. Mol Cancer Res 2006;4:779-792.

71. Konieczkowski DJ, Johannessen CM, Abudayyeh $\mathrm{O}$ et al. A melanoma cell state distinction influences sensitivity to MAPK pathway inhibitors. Cancer Discov 2014:4:816-827.

72. Sztiller-Sikorska M, Koprowska K, Majchrzak K et al. Natural compounds' activity against cancer stem-like or fast-cycling melanoma cells. PLoS One 2014;9:e90783.

73. Santostefano KE, Hamazaki T, Biel NM et al. A practical guide to induced pluripotent stem cell research using patient samples. Lab Invest 2015;95:4-13. 